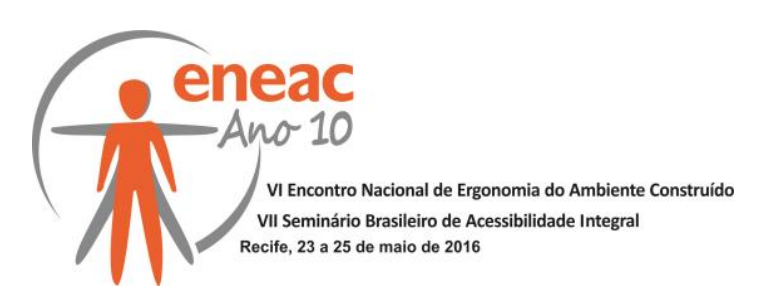

\title{
COMPLEXIDADE DA SINALIZAÇÃO E QUALIDADE PERCEBIDA
}

\author{
GALVEZ, Carmen (1); \\ COSTA FILHO, Lourival (2) \\ (1) Universidade Federal de Pernambuco, Designer \\ e-mail: carmengalvezrb@hotmail.com \\ (2) Universidade Federal de Pernambuco, Doutor em Desenvolvimento Urbano \\ e-mail: lourivalcosta@yahoo.com
}

\begin{abstract}
RESUMO
A pesquisa apresentada teve como objetivo testar o efeito da complexidade da sinalização direcional na qualidade visual percebida. Para tal, realizou uma consulta online, em que os participantes foram solicitados a ranquear nove cenas de ambientes hospitalares pela facilidade informativa de suas sinalizações. As cenas com sinalizações de baixa complexidade foram avaliadas as mais informativas.
\end{abstract}

Palavras-chave: sinalização; complexidade; qualidade percebida.

\begin{abstract}
The research presented aimed to test the effect of signage complexity on perceived visual quality. In order to do this, respondents were asked to complete an online survey, and to rank, in order, nine hospital scenes in terms of the signs' ease of information. The low complexity signage scenes were considered the most informative.
\end{abstract}

Keywords: signage; complexity; perceived quality.

\section{INTRODUÇÃO}

Para garantir a acessibilidade é necessário identificar os elementos que impedem ou restringem a percepção, compreensão, circulação ou apropriação por parte dos usuários dos espaços, bem como os obstáculos de ordem social e psicológica que impedem seu uso efetivo. Esses elementos restritivos são denominados de barreiras (BINS ELY, 2004).

A pesquisa teve como objeto de estudo empírico os elementos de sinalização direcional em ambientes hospitalares, utilizados para facilitar a capacidade de o usuário orientar-se e deslocar-se no espaço. O objeto de estudo teórico, qualidade visual percebida, segundo Nasar (1988), envolve avaliações tanto para o entorno quanto para o sentimento das pessoas sobre ele. Como resultado a ser apurado, a qualidade visual percebida será medida através de julgamentos avaliativos para a sinalização direcional.

Uma característica da sinalização direcional - complexidade - foi destacada para estudo, por sua provável influência na qualidade visual percebida. De acordo com Kaplan e Kaplan (1982), a complexidade contribui para a preferência por envolver o observador.

A partir dessa afirmação de Kaplan e Kaplan (1982), admite-se ser relevante testar o efeito da complexidade da sinalização direcional na qualidade visual percebida, ou seja, verificar o 


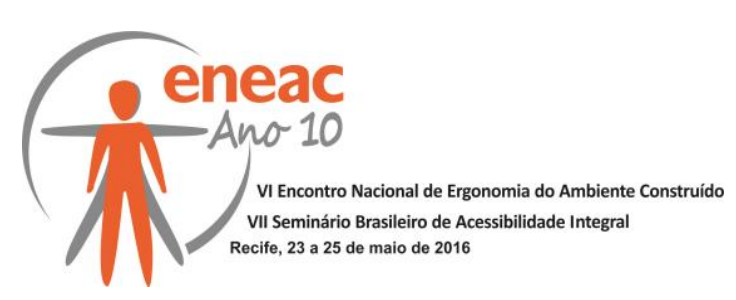

nível de complexidade que está relacionado com a preferência da sinalização direcional em cenas de ambientes hospitalares, segundo a visão dos participantes.

Presumivelmente, a avaliação influencia o comportamento de tal forma que as pessoas são mais propensas a buscarem informações num elemento de sinalização percebido como favorável e evitar outros julgados negativamente. Levando em conta esse argumento, os participantes foram solicitados a ranquear nove cenas de ambientes hospitalares pela facilidade informativa de suas sinalizações.

Buscando responder a essa questão, delineou-se como objetivo desta pesquisa: testar o efeito da complexidade da sinalização direcional na sua qualidade visual percebida.

\section{CONTEÚDO}

Em sintonia com os princípios da acessibilidade, um ambiente deve oferecer condições de navegabilidade segura, confortável e autônoma. Tal condição, torna-se fundamental quando se trata de ambientes públicos, que recebem ampla diversidade de pessoas com diferentes habilidades, capacidades e limitações.

De acordo com Lynch (1997), o contratempo da desorientação interfere na sensação de equilíbrio e bem-estar, podendo trazer implicações de completo desastre.

Para deslocar-se em um ambiente, o indivíduo precisa necessariamente orientar-se, recebendo informação do ambiente através de sua arquitetura e mensagens adicionais, tratar essa informação e agir em função da informação recebida (BINS ELY, 2004). Ainda segundo a autora, diversos fatores podem dificultar ou mesmo impedir o processamento da informação: mensagens em excesso, ambíguas, conflitantes, deficientes ou pouco claras.

Assim sendo, a qualidade visual percebida do ambiente e dos elementos referenciais nele presentes tem efeitos poderosos sobre a experiência do usuário na compreensão do espaço e, consequentemente, na sua capacidade de processar a informação e avaliar o ambiente.

Essa imagem avaliativa surge da pessoa, da coisa observada, e da interação continua entre os dois. Pode variar com a biologia, personalidade, experiências socioculturais, objetivos, expectativas e fatores internos e externos. Pode envolver quantidades variáveis de atividade mental, e, por causa das experiências únicas e da singularidade de cada indivíduo, a imagem avaliativa pode variar entre observadores (NASAR, 2000), embora o autor destaque, adiante, que pesquisas iniciais e estudos recentes têm confirmado um forte consenso sobre as avaliações e as avaliações ambientais, incluindo semelhanças de respostas entre culturas

Levando em conta a possibilidade de respostas consensuais, diversos estudos identificaram seis atributos visuais notáveis na percepção humana: complexidade, ordem, naturalidade, abertura, conservação, estilo (NASAR, 2000). A complexidade foi o atributo visual escolhido nesta pesquisa para testar seu efeito na qualidade percebida da sinalização direcional.

A complexidade se refere ao número e variabilidade de elementos visuais da sinalização direcional em ambientes hospitalares. Quanto mais variáveis os elementos, mais complexa a sinalização aparenta. Variações de elementos pictóricos, materiais, altura, cor, forma, tamanho, disposição de elementos e ornamentação podem adicionar complexidade.

Em teoria, a complexidade aumenta a incerteza e o estímulo, que, por sua vez, provoca o envolvimento das pessoas; pouca complexidade é monótona e cansativa; muita é caótica e estressante, sobrecarregando as pessoas. O nível médio de complexidade parece ser 0 mais agradável, ou ideal. Dentro dessa perspectiva, o tom hedônico da cena (prazer ou beleza) tem sido postulado como tendo a forma de "U" invertido em relação à complexidade (BERLYNE, 1972; WOHLWILL, 1976). 


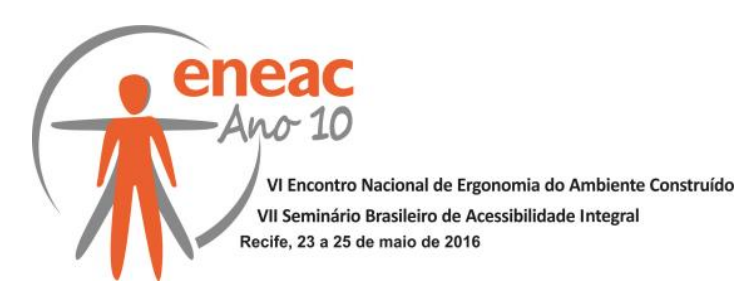

\section{METODOLOGIA}

Levando em conta a potencialidade de testar os efeitos da complexidade da sinalização direcional na qualidade percebida, a atenção voltou-se para uma modalidade de coleta de dados que favorecesse esse processo, o sistema de classificações. Esse procedimento tem outras vantagens; não depende de declarações verbais e permite o uso de materiais visuais.

Quanto a definição dos elementos de estímulos para as classificações, foi considerado um conjunto de nove cenas de ambientes hospitalares com sinalizações direcionais agrupadas em trincas de três diferentes níveis de complexidade visual (baixa, média, alta).

Uma consulta online informou aos entrevistados que não havia respostas certas ou erradas, e que suas respostas seriam mantidas em sigilo e anonimato. Em seguida, solicitava que eles classificassem as nove cenas pela facilidade informativa de suas sinalizações.

No final, 24 sujeitos responderam; a maioria entre 18 e 40 anos e ensino médio completo. Os dados foram analisados qualitativamente, através de uma estrutura de favorecimento, em que cada nível de classificação das cenas - variando em cinco níveis -, recebeu um valor numérico de 1 a 5, sendo a nota 5 para aquela de maior facilidade e a nota 1 para o oposto.

\section{RESULTADOS}

Reitera-se que cada entrevistado classificou nove cenas em termos de sua complexidade. A forma de "U" invertido em relação à complexidade não emergiu. Um grande número de pessoas, inesperadamente, selecionou a sinalização com baixa complexidade como sendo as mais informativas. A complexidade alta, entretanto, conforme postulado, representou o oposto. Este resultado é um indicativo de diferenças individuais nas respostas ou uma gama insuficiente de complexidade nas cenas, para desacelerar a facilidade informativa.

Tais resultados apoiam que a qualidade informativa da sinalização direcional em ambientes hospitalares deve ter baixa variação de elementos pictóricos, materiais, altura, cor, forma, tamanho, disposição de elementos e ornamentação, para garantir a qualidade percebida.

\section{REFERÊNCIAS BIBLIOGRÁFICAS}

BERLYNE, D. E. Ends and meanings of experimental aesthetics. Canadian Journal of Psychology, n. 26, p. 303-325, 1972.

BINS ELY, V. H. Acessibilidade Espacial: Condições necessária para o projeto de ambientes inclusivos. In: MORAES, Anamaria de (Org.). Ergonomia do ambiente construído: ambiente urbano, ambiente público, ambiente laboral. Rio de Janeiro: iUsEr, 2004, p. 17-40

KAPLAN, S.; KAPLAN, R. Cognition and environment: functioning in an uncertain world. New York: Praeger, 1982.

LYNCH, K. A imagem da cidade. São Paulo: Editora Martins Fontes, 1997.

NASAR, J. The evaluative image of places. In W. Bruce Walson, Kenneth H. Craik, Richard H. Price. (Eds.). Person-environment psychology: New directions and perspectives. New Jersey: Lawrence Erlbaum Associates, Inc., 2000.

Environments Aesthetics: theory, research, and applications. New York: Cambridge

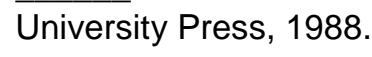

WOHWILL, J. Environmental aesthetics: The environment as a source of affect. In: I. Altmann; J. Wohwill (Eds.), Human behavior and environment, v.1, 37-86, 1976 